\title{
Choices Behind Numbers: a Review of the Major Air Pollution Health Impact Assessments in Europe
}

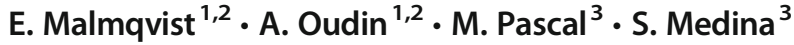 \\ Published online: 5 February 2018 \\ (C) The Author(s) 2018. This article is an open access publication
}

\begin{abstract}
Purpose of Review The aim of this review is to identify the key contextual and methodological differences in health impact assessments (HIA) of ambient air pollution performed for Europe. We limited our review to multi-country reviews. An additional aim is to quantify some of these differences by applying them in a HIA template in three European cities.

Recent Findings Several HIAs of ambient air pollution have been performed for Europe, and their key results have been largely disseminated. Different studies have, however, come up with substantial differences in attributed health effects. It is of importance to review the background contributing to these differences and to quantify their importance for decision makers who will use them. Summary We identified several methodological differences that could explain the discrepancy behind the number of attributable deaths or years of life lost. The main differences are due to the exposure-response functions chosen, the ways of assessing air pollution levels, the air pollution scenarios and the study population. In the quantification part, we found that using risk estimates from the European Study of Cohorts for Air Pollution Effects (ESCAPE) instead of the American Cancer Society (ACS) study could nearly double the attributable burden of ambient air pollution.

This study provides some insights into the differential results in previously published HIAs on air pollution in Europe. These results are important for stakeholders in order to make informed decisions.
\end{abstract}

Keywords Health impact assessment · Air pollution · HIA · Exposure-response function · Health effects

This article is part of the Topical Collection on Susceptibility Factors in Environmental Health

Electronic supplementary material The online version of this article (https://doi.org/10.1007/s40572-018-0175-2) contains supplementary material, which is available to authorized users.

E. Malmqvist

Ebba.Malmqvist@med.lu.se

1 Occupational and Environmental Medicine, Lund University, Lund, Sweden

2 Occupational and Environmental Medicine, Umeå University, Umea, Sweden

3 Institut de Veille Sanitaire, Saint Maurice, France
Abbreviations

ACS American Cancer Society

AHSMOG Loma Linda University Adventist Health and Smog study

APED Air pollution epidemiology database

APHEA Air Pollution and Health: a European Approach project

APHEKOM Improving knowledge and Communication for Decision Making on Air Pollution and Health in Europe

APHEIS Air Pollution and Health: a European Information System

APHENA Air Pollution and Health: a European and North American approach study

CAFE Clean Air for Europe

CI Confidence interval

DALY Disability-adjusted life year 
ESCAPE European Study of Cohorts for Air Pollution Effects

EBD European Perspectives on Environmental Burden of Disease

EU European Union

GBD2000 The Global Burden of Disease due to outdoor air pollution for 2000

GBD2008 Global Burden of Disease from urban outdoor air pollution for 2008

GBD2012 Global Burden of Disease from ambient air pollution for 2012

$\begin{array}{ll}\text { GBD 2010 } & \text { Global Burden of Disease 2010 study } \\ \text { HR } & \text { Hazard ratio } \\ \text { HIA } & \text { Health impact assessment } \\ \text { HRAPIE } & \text { Health risks of air pollution in Europe } \\ \text { ICD } & \text { International Classification of Diseases } \\ \text { IIASA } & \text { International Institute for Applied Systems } \\ \text { MRAD } & \text { Analysis } \\ \text { NO2 } & \text { Minor restricted activity day } \\ \text { NOx } & \text { Nitrogen dioxide } \\ \text { O3 } & \text { Nitrogen oxides } \\ \text { OECD } & \text { Ozone } \\ \text { PM } & \text { Organization for Economic Co-operation and } \\ \text { PM10 } & \text { Development } \\ \text { PM2.5 } & \text { Particulate matter } \\ \text { ppb } & \text { eter smaller than } 10 \mu \text { Particulate matter with an aerodynamic diam- } \\ \text { RAD } & \text { eter smaller than } 2.5 \mu \text { m } \\ \text { REVIHAAP } & \text { Parts per billion } \\ \text { RR } & \text { Restricted activity day } \\ \text { SD } & \text { pollution project } \\ \text { WHO } & \text { Relative risk } \\ \text { YLL } & \text { Standard deviation } \\ & \text { World Health Organization } \\ \text { Years of life lost }\end{array}$

\section{Background}

During the last decades, epidemiological and toxicological studies have provided enough evidence to conduct health impact assessment (HIA) of air pollution $[1,2]$. According to the World Health Organization (WHO), 'HIA is a practical approach used to judge the potential health effects of a policy, programme or project on a population, particularly on vulnerable or disadvantaged groups' [3].

HIA estimates the mortality and morbidity rates due to current levels of air pollution and the public health impact that would be expected if the levels of air pollution would change to a certain extent. An HIA thus can estimate the human health impacts of current policy or implemented actions and can thereby become a useful tool for policymakers and planners. Whilst epidemiologists often study the risk of a disease in the presence of exposure relative to risk of a disease in the absence of exposure, a health impact assessor on the other hand often asks the following: how many excess cases of disease will occur in a population of a certain size due to exposure at a certain dose level? [4]. HIAs generally apply exposure-response functions based on risk estimates from the epidemiology literature in order to relate exposure estimated by air pollution assessment and the scenarios for air quality changes (related to the aim of HIA) to a population at risk and its baseline health status (prevalence and incidence of disease) [5].

The first HIA of air pollution in Europe was conducted in Switzerland and shortly followed by a HIA conducted for France, Switzerland and Austria, the Tri-national study [6]. The objective of the Tri-national study was to highlight the hidden costs of traffic by putting a monetary value on the pollution of air. Several HIAs have since been performed for Europe, and their key results have been largely disseminated. HIAs have most commonly been used in large projects such as the Global Burden of Disease by World Health Organization (WHO) [7-9]. The aim of the HIAs conducted up until present has differed resulting in conflicting conclusions in terms of attributed health effects to air pollution. Within the context of its goals, air pollution scenarios are created, i.e. current levels compared to air quality guideline levels or current levels compared to increased/decreased levels expected to occur due to certain policies. Some of the underlying HIA aims may be so fundamentally different that they do not allow for comparison of the results attained, i.e. comparing the impact of a specific local road policy in Antwerp, Belgium [10] with a broader climate change policy in five cities in Europe [11].

But even studies with comparable aims have arrived at substantially different attributed health effects. As an example, the Global Burden of Disease (GBD) 2010 reports a worldwide air pollution related death toll that is four times bigger than that of GBD 2000. The differences are according to Organization for Economic Co-operation and Development (OECD) partly explained by increasing air pollution levels in Southeast Asia and diminishing competing risks from poverty related disease and mortality and partly by the methodology applied. Two other methodological reasons for this discrepancy reported by OECD are firstly improved exposure assessments by new remote sensing satellite-based technology instead of spatially scarce numbers of monitoring stations and secondly a more comprehensive and rigorous methodology to assemble and analyse epidemiological findings [12]. Other methodological differences mentioned in the literature are related to the study area [13]. Another difference is the way they expressed the mortality or morbidity impacts such as attributable deaths or life expectancy [13]. 


\section{Aim}

The aim of this project is to identify key contextual and methodological differences used by the major air pollution related HIAs in Europe in the period of 2000-2012. An additional aim was to quantify some of these differences using a template provided by the project Improving knowledge and Communication for Decision Making on Air Pollution and Health in Europe (APHEKOM).

\section{Method}

The HIAs we reviewed estimate mortality and morbidity rates due to current levels of air pollution in Europe and the public health benefits that would be incurred if the levels of air pollution would decrease to a varying and specified extent.

In this review, we will focus on (a) the exposure-response functions selected (based on risk estimates from the epidemiological literature), (b) air pollution exposure assessment, (c) scenarios of air pollution changes and (d) the selection of population at risk as proposed by a previous review [13]. With air pollution scenarios, we mean the hypothetical changes in air pollution levels relating to the aim of the HIAs, i.e. the difference in effect between baseline air pollution levels (often current levels) and those that would (sometimes hypothetical) occur by adhering to a specific policy.

In this article, (1) we present and review the differences in recent HIAs in Europe, and (2) we use a simple exercise using those differences we identified to quantify their importance.

\section{Part 1: Literature Review}

This review is not a systematic review of all HIAs on air pollution. Criteria are large HIAs covering a large proportion of Europe (defined as more than one country) with the aim of guiding international air pollution policies. The HIAs included here have been chosen a priori by the APHEKOM group. In addition, we have added the Health risks of air pollution in Europe (HRAPIE) project and the Tri-national study to fulfil abovementioned criteria. We have included three WHOfunded GBD studies to identify the methodological changes that have occurred over the years. The information presented in this review is based on available technical reports and articles.

We included the following HIAs:

1) Improving knowledge and Communication for Decision Making on Air Pollution and Health in Europe (APHEKOM)

2) Air Pollution and Health: a European Information System (APHEIS)
3) Clean Air For Europe (CAFE)

4) European Perspectives on Environmental Burden of Disease (hereafter referred to as EBD)

5) Global Burden of Disease due to outdoor air pollution for 2000 (hereafter referred to as GBD2000)

6) Global Burden of disease from urban outdoor air pollution for 2008 (hereafter referred to as GBD2008)

7) Global Burden of disease from ambient air pollution for 2012 (hereafter referred to as GBD2012)

8) Tri-national study

9) HRAPIE

\section{Part 2: Quantification of Differences}

To quantify the reviewed differences, we have used an HIA online tool developed by the APHEKOM project and freely available at http://si.easp.es/aphekom/ to conduct HIAs under alternate assumptions. This online tool provides guidelines and Excel spreadsheets and uses the general framework recommended by WHO for performing an HIA. In this quantification exercise, we have based our analyses on measured annual means of particulate matter with an aerodynamic diameter smaller than $2.5 \mu \mathrm{m}\left(\mathrm{PM}_{2.5}\right)$ in Stockholm, Budapest and Paris for the years 2004-2006. Thus, this should not be interpreted as a complete HIA but rather as an exercise to quantify and show how methodological differences affect the estimates. The cities were chosen based on their representativeness of European air pollution levels with one city Stockholm, Sweden with relatively low levels (mean levels of $\mathrm{PM}_{2.5}$ for 2004-2006 is $9 \mu \mathrm{g} / \mathrm{m}^{3}$ ); Paris, France with higher levels (mean levels of $\mathrm{PM}_{2.5}$ for 20042006 is $16 \mu \mathrm{g} / \mathrm{m}^{3}$ ); and Budapest, Hungary with some of the highest levels of air pollutants (mean levels of $\mathrm{PM}_{2.5}$ for $2004-2006$ is $34 \mu \mathrm{g} / \mathrm{m}^{3}$ ) (more details on levels in Table S1 in the Supplement). Budapest was also chosen to help understand how missing $\mathrm{PM}_{2.5}$ measurements may influence results when one uses particulate matter with an aerodynamic diameter smaller than $10 \mu \mathrm{m}\left(\mathrm{PM}_{10}\right)$ measurements as an approximation for the missing values of $\mathrm{PM}_{2.5}$ with differing $\mathrm{PM}_{10} / \mathrm{PM}_{2.5}$ ratios.

The three cities have also different age distributions and thus baseline mortality and morbidity rates (see Table 1). As an example, the population in Stockholm was older compared with the other two cities.

We made the following methodological choices for our alternate HIA calculations:

a) We derived the exposure response-function from allcause mortality risk estimates in the American Cancer Society Study by Pope et al. (hereafter referred to as ACS study) that reported hazard ratios 
Table 1 Age, population and mortality distribution in the three cities example for the years 2004-2006

\begin{tabular}{|c|c|c|c|c|c|c|}
\hline $\begin{array}{l}\text { Age } \\
\text { (years) }\end{array}$ & $\begin{array}{l}\text { Total population Stockholm } \\
\text { (age distribution } \% \\
\text { of population) }\end{array}$ & $\begin{array}{l}\text { Total mortality } \\
\text { Stockholm } \\
\text { 2004-2006 }\end{array}$ & $\begin{array}{l}\text { Total population Paris } \\
\text { (age distribution } \% \\
\text { of population) }\end{array}$ & $\begin{array}{l}\text { Total mortality } \\
\text { Paris } \\
2004-2006\end{array}$ & $\begin{array}{l}\text { Total population Budapest } \\
\text { (age distribution \% } \\
\text { of population) }\end{array}$ & $\begin{array}{l}\text { Total mortality } \\
\text { Budapest } \\
\text { 2004-2006 }\end{array}$ \\
\hline $30-34$ & $114,331(14.3)$ & $183(0.6)$ & $556,968(14.3)$ & $1094(0.9)$ & $147,248(12.7)$ & $309(0.5)$ \\
\hline $35-39$ & $102,236(12.8)$ & $212(0.6)$ & $504,035(12.9)$ & $1526(1.3)$ & $124,847(10.8)$ & $456(0.7)$ \\
\hline $40-44$ & $93,698(11.7)$ & $289(0.9)$ & $470,741(12.1)$ & $2332(2.0)$ & $95,126(8.2)$ & $758(1.1)$ \\
\hline $45-49$ & $83,059(10.3)$ & $451(1.4)$ & $428,835(11.0$ & 3471 (2.9) & $104,103(9.0)$ & $1634(2.4)$ \\
\hline $50-54$ & $77,261(9.6)$ & $776(2.3)$ & $410,073(10.5)$ & $5253(4.5)$ & $145,540(12.6)$ & $3546(5.2)$ \\
\hline $55-59$ & $81,444(10.2)$ & $1369(4.3)$ & $404,174(10.4)$ & $6886(5.9)$ & $125,165(10.8)$ & $4254(6.2)$ \\
\hline $60-64$ & $66,272(8.3)$ & $1656(5.0)$ & $274,860(7.1)$ & $6320(5.4)$ & $112,722(9.7)$ & $5237(7.6)$ \\
\hline $65-69$ & $45,195(5.6)$ & $1876(5.7)$ & $215,004(5.5)$ & $7459(6.4)$ & $83,370(7.2)$ & $5504(8.0)$ \\
\hline $70-74$ & $37,678(4.7)$ & $2476(7.5)$ & $200,488(5.2)$ & $10,565(9.1)$ & $73,578(6.4)$ & 7459 (10.9) \\
\hline $75-79$ & $36,131(4.5)$ & 3937 (11.9) & $178,049(4.6)$ & $14,594(12.5)$ & $66,662(5.8)$ & $10,623(15.5)$ \\
\hline $80-84$ & $33,482(4.2)$ & $6362(19.2)$ & $138,960(3.6)$ & $19,248(16.5)$ & $47,910(4.1)$ & $12,552(18.3)$ \\
\hline$>85$ & $29,585(3.7)$ & $13,558(40.9)$ & $108,313(2.8)$ & $37,895(32.5)$ & $30,317(2.6)$ & $16,281(23.7)$ \\
\hline Total & 800,372 & 33,145 & $3,890,498$ & 163,888 & $1,156,588$ & 68,613 \\
\hline
\end{tabular}

(HR) of 1.06 (CI 1.02-1.11) per $10 \mu \mathrm{g} / \mathrm{m}^{3}$ increment of $\mathrm{PM}_{2.5}$ for total mortality [14]; alternatively, we used the new European Study of Cohorts for Air Pollution Effects (ESCAPE) results by Beelen et al. 2014, hereafter referred to as ESCAPE study with an HR of 1.07 (CI $1.02-1.13$ ) per $5 \mu \mathrm{g} / \mathrm{m}^{3}$ increment of $\mathrm{PM}_{2.5}$ [15•] for natural all-cause mortality after transforming the ESCAPE HR to a $10-\mu \mathrm{g} / \mathrm{m}^{3}$ increment of $\mathrm{PM}_{2.5}$ (HR of 1.14 (95\% CI 1.09-1.20).

b) Levels of air pollutants can depend not only on the accuracy of modelling (which we unfortunately could not access) but also on chosen strategies with missing measurement data. Some parts of the world lack/lacked $\mathrm{PM}_{2.5}$ measurements to deal with this issue; some of the HIAs we reviewed (see Table S4 in the Supplement) converted the measured pollutant into the desired pollutant by a simplified ratio. This ratio varied by HIA (see Table S4 in the Supplement). We evaluated the changes in estimates when using different conversion rates from $\mathrm{PM}_{10}$ to $\mathrm{PM}_{2.5}$, specifically using 0.5 or 0.7 , to replace missing data for $\mathrm{PM}_{2.5}$ based on $\mathrm{PM}_{10}$ measures.

c) The attributed health effects of air pollution will hypothetically depend on what size changes are expect$\mathrm{ed}$, the air pollution scenarios. We evaluated three $\mathrm{PM}_{2.5}$ scenarios found in our literature review: levels corresponding to WHO air quality guidelines $(10 \mu \mathrm{g} /$ $\mathrm{m}^{3}$ ) (scenario 1 in our literature review), a general $5 \mu \mathrm{g} / \mathrm{m}^{3}$ reduction from current levels (scenario 3 in our literature review) or setting the expected air pollution at zero (scenario 6 in our literature review).

d) We briefly evaluated the role the composition of the study population plays in terms of age distribution and baseline mortality by studying three different European cities, Stockholm, Paris and Budapest.

\section{Results}

\section{Part 1: Literature Review}

\section{Exposure-Response Functions Based on Risk Estimates From Epidemiology}

Most studies used risk estimates for cause-specific mortality for particulate matter (PM) as exposure-response function. There were, however, some differences in the risk estimates chosen as well as the underlying causes (diseases) behind mortality. APHEIS, CAFE, EBD and GBD 2000 and 2008 used risk estimates from Pope et al. [14] and only modelled HIAs for cardiopulmonary and lung cancer mortality. APHEKOM used a later study by Pope et al. [16] on cardiovascular mortality and GBD 2012 used Burnett et al. for integrated exposure-response function (based on risk estimates of mortality from ischemic heart disease, cerebrovascular disease (stroke), chronic obstructive pulmonary disease (COPD) and lung cancer in adults and acute lower respiratory infection in children) [17•].

Other studies used risk estimates for all-cause mortality or a combination of all cause and cause-specific mortality (see Table S2 in the Supplement). Whilst all-cause mortality should include all causes of death, this is sometimes limited to natural all-cause mortality excluding deaths by accidents or trauma. Morbidity due to longterm exposure to PM was only included in some but not all studies (see Table S3 in the Supplement).

The above-mentioned morbidity/mortality rates are for long-term exposure (months to years) to PM, but air pollution may also exert its effects also after short-term exposures (days). The most commonly used short-term effect of PM in 
HIA is infant mortality (for more, see Table S3 in the Supplement). Both CAFE and GBD (all) addressed infant mortality. In CAFE, they relied on Woodruff et al. with a relative risks (RR) of 1.04 for mortality in the first 2 months of life with each $10 \mu \mathrm{g} / \mathrm{m}^{3}$ increase in $\mathrm{PM}_{10}$ [18]. In GBD2000, 2008 and 2012, they used a meta-analysis combining five times series that estimated a meta-RR for respiratory mortality in children under 5 years of age $[1.017 ; 95 \%$ confidence interval (CI) 1.003, 1.030] [19]. In GBD 2012, the respiratory mortality for children under 5 years of age is included in the integrated risk function from Burnett et al. [17•]. In addition, some HIAs included short-term effects on chronic bronchitis and hospitalizations for respiratory/cardiac diseases (see Table S3 in the Supplement). Health effects due to pollutants other than $\mathrm{PM}\left(\mathrm{PM}_{10}\right.$ and $\left.\mathrm{PM}_{2.5}\right)$ were only considered for ozone in APHEKOM, CAFE, EBD and HRAPIE and for $\mathrm{NO}_{2}$ in HRAPIE [1].

\section{Air Pollution Assessment}

The levels of air pollutants were generated either from measurements from monitoring stations or by modelling (see Table S4 in the Supplement). In the APHEIS and APHEKOM and GBD 2000 and 2008 projects, PM $_{2.5}$ was assessed from monitoring stations and if $\mathrm{PM}_{2.5}$ was not measured, several studies used $\mathrm{PM}_{10}$ measurement data and applied varying conversion rates $(0.5-0.7)$ [7, 8, 20-22]. The Tri-national study used a combination of measurements of total suspended particulates, black smoke, $\mathrm{PM}_{10}$ and nitrogen oxides $\left(\mathrm{NO}_{x}\right)$ (for all countries) and a dispersion model (only available for Switzerland) to assess exposure to $\mathrm{PM}_{10}$. In HRAPIE, the experts concluded that Europe-wide modelling for particles is only available for $\mathrm{PM}_{2.5}$; so, in cases where health effects are expressed against $\mathrm{PM}_{10}$ in the literature, a conversion has to be employed to assess the equivalent impact per unit of $\mathrm{PM}_{2.5}$. This is achieved by multiplying the exposure-response function for $\mathrm{PM}_{10}$ by a factor of 1.54 , assuming a $\mathrm{PM}_{2.5} / \mathrm{PM}_{10}$ ratio of 0.65 [1].

For CAFE, $\mathrm{PM}_{2.5}$ was modelled using the European Monitoring and Evaluation Programme (EMEP) Eulerian model with a resolution of $50 \times 50 \mathrm{~km}$ including only anthropogenic emissions [23-26]. For EBD, the pollutants were modelled by the European Topic Centre on Air and Climate Change (ETC/ACC) with $10 \mathrm{~km} \times 10 \mathrm{~km}$ resolution [19]. For GBD 2012, annual mean estimates of $\mathrm{PM}_{2.5}$ were modelled with a grid of $0.1^{\circ} \times 0.1^{\circ}$ (approximately $11 \times 7 \mathrm{~km}$ for a centroid in Europe) [9, 21, 27].

Ozone assessment was only included in the APHEKOM, CAFE, HRAPIE and EBD projects. In APHEKOM, ozone was assessed by times series from monitoring stations, using the daily maximum of the $8 \mathrm{~h}$ mean. For short-term effects, measurements for a whole year were used and for long-term effects, measurements were restricted to data from April to September [28]. In CAFE, ozone above a cut-off point of a daily maximum 8-h mean of $35 \mathrm{ppb}$ (SOMO35) was calculated using the EMEP Eulerian model with a resolution of $50 \times 50 \mathrm{~km}$ including reported anthropogenic emissions [23-25, 29]. For EBD, the ozone levels (SOMO35) were modelled using AirBase data and air quality maps [19]. Also, the HRAPIE experts recommended an ozone cut-off concentration of $35 \mathrm{ppb}$.

Levels of pollutants differ by included areas and years. Emissions of air pollutants in the EU have generally dropped from 2002 to 2011 by $14 \%$ for $\mathrm{PM}_{10}$ and by $16 \%$ for $\mathrm{PM}_{2.5}$ mainly due to tighter vehicle emission standards; however, increasing urbanization makes more people exposed to higher levels [12].

\section{Air Pollution Scenarios}

The HIAs relate the health impact of the assessed air pollution levels during the study period to a counterfactual level that is assumed by an air pollution scenario. In APHEKOM, APHEIS and GBD2008, the air pollution scenario (scenario 1) assumes that air pollution health effects could have been avoided if the mean annual WHO Air Quality Guidelines (AQG) values of $\mathrm{PM}_{2.5}=$ $10 \mu \mathrm{g} / \mathrm{m}^{3}$ had been implemented (used as counterfactual values) [8, 19, 20, 30]. The Tri-national study used a counterfactual level of $7.5 \mu \mathrm{g} / \mathrm{m}^{3}$ for $\mathrm{PM}_{10}$ (scenario 2). APHEIS and APHEKOM also studied other reduction scenarios for PM or ozone such as a reductions of $5 \mu \mathrm{g} / \mathrm{m}^{3}$ modeled/measured levels at study year [20] (scenario 3). For CAFE, the RAINS model was used with two different scenarios the first, scenario 4, is called the current legislation (CLE) which assumes the successful implementation of all presently decided emissionrelated legislation in all countries of the EU-25 [31]. The second scenario, scenario 5 , is the maximum technical feasible reduction case (MFR) [31] which also assumes full implementation of the presently available most advanced technical emission control measures in the year 2020 (but specific reduction levels of scenarios 4 and 5 are varying in time and no specific reduction levels can be presented here) [23-26]. For EBD, no threshold was used [19] and levels were compared to a scenario in which air pollution levels would be reduced down to zero, scenario 6. For GBD 2000, the burden of disease was estimated with respect to counterfactual concentrations of $7.5 \mu \mathrm{g} / \mathrm{m}^{3}$ for $\mathrm{PM}_{2.5}$ or $15 \mu \mathrm{g} / \mathrm{m}^{3}$ for $\mathrm{PM}_{10}$, scenario 7. In the GBD 2012, the counterfactual concentration, scenario 8 , was selected to be between 5.8 and $8.8 \mu \mathrm{g} / \mathrm{m}^{3}$, depending on area [17•]. HRAPIE experts recommend assuming benefits of any reduction in exposure, including at very low modelled levels of PM2.5 [1] but no specific scenarios are presented. 


\section{Study Populations}

The APHEKOM and APHEIS projects were based on 25 and 26 cities, respectively, in 12 countries and only included members of the population over 30 years of age [28]. For CAFE, the study area was based on the EU-25 countries $[23,25,31]$. The EBD was based on six countries: Belgium, Finland, France, Germany, Italy and the Netherlands $[19,30]$. The GBDs were made globally but results are also presented regionally, European data were divided into (1) high-income and (2) low- and middleincome countries. For the GBD 2000 and 2008, only urban air pollution was accounted for by restricting to cities with more than 100,000 inhabitants and to national capitals. This was extended to whole populations (regardless of the number of inhabitants in an area) in GBD 2012 [7, 8, 32]. The study populations are further described in the Supplement. HRAPIE experts recommended estimation of most mortality effects in adult populations (age 30+ years) as most of the health effect evidence comes from studies that focus on populations in this age group [1]. The Tri-national study also used this cut-off for their mortality studies [6].

\section{Presentation of Reviewed Results}

More detailed definitions are provided in the Supplement. In APHEKOM, APHEIS, GBD 2000, GBD 2008 and GBD 2012, the results are presented as premature attributable deaths [20]. In GBD 2000, some results were also presented as DALY (consisting only of years of life lost (YLL) due to premature mortality) [32]. In CAFE, the mortality effects were expressed as change in longevity by years of life lost and in the cost-benefit analysis value of a life year. But due to the methodological difficulties of assessing different age-specific values of a life year, attributable deaths were also calculated. Due to methodological problems, life tables were not used in CAFE [23-25]. In EBD, results were presented as DALYs, without age weighting or discounting [19]. No time lags were used between assumed changes in pollution and consequent changes in death rates in any of the studies included in the present review (Table 2).

\section{Part 2: Quantification}

\section{Exposure-Response Functions Based on Risk Estimates From Epidemiology}

We illustrated the implication of using different risk estimates as exposure-response functions by comparing risk estimates based on the ACS study with those based on the ESCAPE study. Using the ESCAPE risk estimates
Table 2 Definitions and results presented by the HIA authors

\begin{tabular}{lll}
\hline Study & Results & Definition of impact \\
\hline AHEKOM & 19,000 & Deaths $^{\mathrm{a}}$ \\
APHEIS & 11,375 & Deaths $^{\mathrm{a}}$ \\
CAFE (CBA) & 8.1 & YLL $^{\mathrm{b}}$ (months) \\
EBD & $4500-10,000$ & DALYs $^{\mathrm{c}} /$ million people $^{\mathrm{a}}$ \\
GBD 2005 & 23000 & Deaths $^{\mathrm{a}}$ \\
GBD 2008 & 67,000 & Deaths $^{\mathrm{a}}$ \\
GBD 2012 & 279,000 & Deaths $^{\mathrm{a}}$ \\
HRAPIE & n.a. & \\
Tri-national & 40,000 & Deaths $^{\mathrm{a}}$ \\
\hline
\end{tabular}

n.a. not applicable

${ }^{\text {a }}$ Deaths refer to premature attributable deaths here due to mainly longterm air pollution exposure

${ }^{\mathrm{b}}$ Years of life lost

${ }^{\mathrm{c}}$ Disability adjusted life years

${ }^{\mathrm{d}}$ In the GBD reports, we used the EUR A countries

and different scenarios changed the results dramatically (Table 3). Using the risk estimate from ESCAPE more than doubled the estimated attributed deaths (see Table 3 below and Figs. S1, S2 and S3 in the Supplement for more detailed results).

\section{Air Pollution Assessment}

We evaluated the consequences of using different conversion rates for $\mathrm{PM}_{10}$ to $\mathrm{PM}_{2.5}$ by using the ratios $(0.5$ or 0.7$)$ to estimate $\mathrm{PM}_{2.5}$ from $\mathrm{PM}_{10}$. Only Budapest lacked $\mathrm{PM}_{2.5}$ measurements; using a ratio of 0.5 instead of 0.7 did not change the results in scenario 3 (as expected since the ratio does not affect an absolute reduction) but reduced the attributed death to 156 (per 100,000) instead of 255 (per 100,000) in scenario 1 and 259 instead of 353 in scenario 6 (numbering of scenarios can be found below).

\section{Air Pollution Scenarios}

We illustrate the effects using three scenarios:

a) The compliance with WHO Air Quality Guidelines $\left(10 \mu \mathrm{g} / \mathrm{m}^{3}\right)$ (scenario 1) used in GDB 2008, APHEIS and APHEKOM, which is the most conservative approach

b) The $5 \mu \mathrm{g} / \mathrm{m}^{3}$ reduction used in APHEIS and APHEKOM (scenario 3), which could somewhat be representable for a hypothetical general reduction in emissions (with new emission standards or low emission zones) 
Table 3 Total number of attributed death and population weighted (per 100,000) for the three cities for three air pollution $\left(\mathrm{PM}_{2.5}\right) \mathrm{scenarios}$ and two different exposure-response functions

\begin{tabular}{|c|c|c|}
\hline Air pollution scenarios in literature review & $\begin{array}{l}\text { E-R function from ESCAPE }{ }^{1} \\
\# \text { of deaths (deaths per } 100,000 \text { ) } \\
\text { Total }\end{array}$ & $\begin{array}{l}\text { E-R function from } \mathrm{ACS}^{2} \\
\text { \# of deaths (deaths per 100,000) } \\
\text { Total }\end{array}$ \\
\hline Scenario 1; WHO AQG $\left(10 \mu \mathrm{g} / \mathrm{m}^{3} \mathrm{PM}_{2.5}\right)$ & $9234(608)$ & $4375(292)$ \\
\hline Scenario $3 ; 5 \mu \mathrm{g} / \mathrm{m}^{3}$ reduction of $\mathrm{PM}_{2.5}$ & 4617 (276) & $2090(126)$ \\
\hline \multirow[t]{2}{*}{ Scenario 6; null $\left(0 \mu \mathrm{g} / \mathrm{m}^{3}\right) \mathrm{PM}_{2.5}$} & $16,965(1059)$ & $8211(518)$ \\
\hline & Budapest & Budapest \\
\hline Scenario 1; WHO AQG $\left(10 \mu \mathrm{g} / \mathrm{m}^{3} \mathrm{PM}_{2.5}\right)$ & $6108(528)$ & $2952(255)$ \\
\hline Scenario $3 ; 5 \mu \mathrm{g} / \mathrm{m}^{3}$ reduction of PM2.5 & $1450(125)$ & $657(57)$ \\
\hline \multirow[t]{2}{*}{ Scenario 6; null $\left(0 \mu \mathrm{g} / \mathrm{m}^{3}\right) \mathrm{PM}_{2.5}$} & $8167(706)$ & $4079(353)$ \\
\hline & Paris & Paris \\
\hline Scenario 1 ; WHO AQG $\left(10 \mu \mathrm{g} / \mathrm{m}^{3} \mathrm{PM}_{2.5}\right)$ & $3126(80)$ & $1423(37)$ \\
\hline Scenario $3 ; 5 \mu \mathrm{g} / \mathrm{m}^{3}$ reduction of PM2.5 & $2466(63)$ & $1116(29)$ \\
\hline \multirow[t]{2}{*}{ Scenario 6; null $\left(0 \mu \mathrm{g} / \mathrm{m}^{3}\right) \mathrm{PM}_{2.5}$} & $7517(193)$ & $3543(91)$ \\
\hline & Stockholm & Stockholm \\
\hline Scenario 1 ; WHO AQG $\left(10 \mu \mathrm{g} / \mathrm{m}^{3} \mathrm{PM}_{2.5}\right)$ & $0(0)$ & $0(0)$ \\
\hline Scenario $3 ; 5 \mu \mathrm{g} / \mathrm{m}^{3}$ reduction of PM2.5 & $701(88)$ & $317(40)$ \\
\hline Scenario 6; null $\left(0 \mu \mathrm{g} / \mathrm{m}^{3}\right) \mathrm{PM}_{2.5}$ & $481(160)$ & $589(74)$ \\
\hline $\begin{array}{l}\text { 1. HR of } 1.14 \text { per } 10 \mu \mathrm{g} / \mathrm{m}^{3} \text { increase in } \mathrm{PM}_{2.5}[15] \\
\text { 2. HR of } 1.06 \text { per } 10 \mu \mathrm{g} / \mathrm{m}^{3} \text { increase in } \mathrm{PM}_{2.5}[14]\end{array}$ & & \\
\hline
\end{tabular}

c) The null air pollution scenario from EBD (scenario 6) (and in one calculation in CAFE), which represents the least conservative approach

\section{Study Populations}

We conducted stratified analyses for Stockholm, Paris and Budapest, and the study population has a large impact due to the combination of exposure levels and demography as illustrated in Figs. S1, S2 and S3 in the Supplement.

\section{Discussion}

Our review has identified large differences in HIA methods applied across studies. Regarding the outcomes, some studies have focused on mortality; others have also included effects on morbidity such as hospitalization for respiratory diseases. The HIAs also differ with respect to long-term or short-term health effects or both. As epidemiological evidence is evolving, the options of what to include in an HIA increase and will thus influence the results that an HIA produces. The results of the HIA will also heavily depend on which epidemiological mortality study/studies were selected to derive the exposure response function. In our calculations, we quantified some of these differences by using more recently published results by ESCAPE on mortality to replace the commonly used mortality effect estimates from the ACS study (see Figs. S1, S2 and S3 in the Supplement). We illustrated that, when using the ESCAPE risk estimates, the estimated number of deaths attributable to air pollution nearly doubled compared with using the risk estimates based on ACS study [14]. Whilst the ACS study [14] studied total mortality, the ESCAPE study [15•] limited death to natural cause mortality, hence excluding deaths by accidents or crimes. Furthermore, whilst the ACS study relies solely on exposure differentials between cities, the ESCAPE study used an exposure assessment that also included within city variations in exposure. Jerrett et al. [33] revised the data from ACS study with a model of more spatially refined exposures and reported that effect estimates increased to $1.14,95 \% \mathrm{CI}$ : $1.11-1.17$ per $10 \mu \mathrm{g} / \mathrm{m}^{3}$ increment in $\mathrm{PM}_{2.5}$. Interestingly, these estimates are much more in line with the estimates derived by ESCAPE emphasizing the importance of the choice of exposure assessment models when deriving exposure response functions. There was some difficulty in reviewing morbidity health outcomes and whether they were related to long- or short-term (acute) effects in the HIAs due to lack of reporting. Sometimes, estimates from a short-term effect were used as a proxy for long-term effects, such as for 'days of restricted activity', but this was not always clearly stated.

Attributable death in epidemiology refers the number of (premature) deaths attributable to the factor(s) of interest. But this does not mean that removal of exposure will permanently reduce the number of death. Death are due to happen anyway but can be postponed, and exposure to air pollution is but one of several risk 
factors that can contribute to development of chronic diseases and ultimately death [34]. Air pollution is a mixture of gases and particles in the air, and each component can have different health effects. Primarily, previous studies have focused on the impact of particle exposure measured as $\mathrm{PM}_{2.5}$ or $\mathrm{PM}_{10}$; however, some studies have also included the effects of ozone. $\mathrm{NO}_{x}$ or nitrogen dioxide $\left(\mathrm{NO}_{2}\right)$ is not accounted for, in order to avoid double counting mixture effects, as $\mathrm{PM}$ and $\mathrm{NO}_{x} / \mathrm{NO}_{2}$ may have similar or same sources and/or are markers for same mixture effect of air pollution. However, increasing evidence of independent effect of $\mathrm{NO}_{2}$, HRAPIE opened up for using $\mathrm{NO}_{2}$ estimates but to avoid double counting [1].

Moreover, modelled versus measured air pollutant levels both have advantages and disadvantages. Modelled levels depend on many factors used as input into the model, for example only including anthropogenic emissions such as in CAFE will results in lower total levels than when accounting for both anthropogenic emissions and biogenic emissions such as in EBD and GBD 2012. This might impact the counterfactual level if using a cut-off such as adhering to WHO air quality guidelines. The accuracy of the modelled levels will also depend on the spatial (or temporal) resolution of the model [33•, 35]; CAFE used a resolution of $50 \times 50 \mathrm{~km}$ whilst EDB and GDB 2012 used $10 \times 10 \mathrm{~km}$ and $0.1^{\circ} \times 0.1^{\circ}$ (which is approx. $7 \times 11 \mathrm{~km}$ in Europe). Measured levels on the other hand have an even cruder spatial resolution often depending on one or few measurements per city for the whole city population, which might reflect poorly exposure at a residential address often used nowadays in epidemiological studies [33•, 35]. Moreover, $\mathrm{PM}_{10}$ was transformed to $\mathrm{PM}_{2.5}$ by using a ratio in several studies, an approach with evident weaknesses. The $\mathrm{PM}_{10} / \mathrm{PM}_{2.5}$ ratio varies by study. Furthermore, some studies included effects of ozone whilst other HIAs were restricted to particles only. The negative health impact estimated in the HIA would increase if pollutants other than PM and ozone were included but a conservative approach is often used to avoid double counting of effects of shared sources of exposure that will produce an overestimation of the health impacts [6].

Study year could also play a role; PM and ozone levels vary between years not only due to policy actions but also due to meteorological factors. Careful consideration should be made especially for years with abnormal mean levels of air pollutants. This can be accounted for by using means over several years.

As discussed previously by Medina et al., there are two different ways of assessing the quantification of health impact in the HIAs: the predictive and the counterfactual approaches. The predictive approach assesses future health consequences of public policies applied today or in a given time frame; it requires making assumptions about future trends in demographics and health status, time needed to achieve pollutant reduction and the time lag between pollutant reduction and improved health. The counterfactual approach compares the current health status of the population to a hypothetical one had the same population not been exposed, and it uses the epidemiological concept of an attributable fraction to generate its estimates. Whereas the counterfactual approach might be more useful to quantify the health burden of air pollution and encourage action, the predictive approach might be more useful to show stakeholders the benefits of implementing a specific concrete policy they developed [36]. The predictive approach will however rely on additional assumptions, such as the success of policy implementations or baseline disease rate changes due to other causes, and it is important that those are stated clearly.

Furthermore, populations may differ in terms of baseline risk factors including age resulting in different baseline morbidity/mortality rates for each country. It is a wellknown fact that effect modifiers limit the generalizability of epidemiologic results across different populations [37]. Source of baseline health data, disease definitions and study period modeled can strongly influence results and the importance of the latter has been highlighted in several reviews [38, 39]. Generally, this is less of a problem in Europe where consistent definitions of and procedures to collect disease/ mortality data are available, but ICD code changes over time can still influence results. Other countries or health end points might have less standardized data available. Generally, agespecific mortality rates by country are widely available and in Europe, this is also true for morbidity rates.

When considering and aggregating number of deaths, it should be kept in mind that, eventually, everyone dies but those at older ages are at higher risks [23-25]. This has been exemplified in our quantification, and whilst it is easily understood that attributable deaths are larger for Budapest with a larger annual mean for $\mathrm{PM}_{2.5}$, it might be harder to understand for Stockholm with a lower annual mean for $\mathrm{PM}_{2.5}$ than Paris. This can be explained by the differences in age distributions, i.e. Stockholm has an older population than Paris and thus a larger population vulnerable and at risk of dying when exposed. This might also be true for unmeasured risk factor distributions that differ between cities. This issue depends on how we present our results, i.e. as number of premature deaths or disability adjusted life years (DALY). For more detailed discussion of this issue and recommendation for the use of terms such as 'average loss of life expectancy', refer to [34].

There is an ongoing discussion whether future years of healthy life are valued less than those at present time (discounting) and if a year lived as a young adult is worth more than a year lived at younger or older ages. This can be accounted for by discounting or age weighting the results and is optional when calculating DALYs. For example the EBD has chosen not to discount or age weight their estimates as it often makes health impacts in children weigh less with the argument that this would not be in line with the priorities set in the European Health Action Impact plan (WHO 2010b) that made children's health a priority [19]. Given the European Health Action Plan, it can also be argued that more negative 
outcomes by air pollution in early years, i.e. birth outcomes, could be included in HIAs of air pollution.

Finally, we would like to make some suggestions for future HIAs. It is important to carefully consider the exposure assessment methods and use better and/or cheaper models validated with measurement data at several sites. The effect of using a ratio to transform $\mathrm{PM}_{10}$ to $\mathrm{PM}_{2.5}$ will be less of a problem in the future when $\mathrm{PM}_{2.5}$ measurements are more widespread. It is also important to note that the field of air pollution epidemiology is constantly evolving with evidence for new health outcomes (i.e. reproductive outcomes, autism, Alzheimer, diabetes, cognitive functions in children), and new effect estimates are derived and can be used for updating exposure response functions for HIAs such as in ESCAPE [15•]. We also need to consider in which situations one of the two HIA approaches may be most relevant: predictive or counterfactual approach. The aim of HIAs might also be different and should be considered when interpreting results.

\section{Conclusion}

We have identified several methodological differences that explain the discrepancy of the estimated number of attributable deaths or DALYs in recent HIAs. The main differences we identified are the exposure response functions used, the ways air pollution levels were assessed, the aim of the HIA (and thus the air pollution scenarios chosen) and the risk factor characteristics of the study population. By using the dose-response function from the ESCAPE project [15•], the estimated number of deaths attributable to air pollution nearly doubled compared with the dose-response function from the ACS study [14]. Making assumptions that go into these results more transparent and showing different scenarios is important for stakeholders in order to take informed decisions. Thus, both aims and assumptions need to be clearly described when presenting results from HIA and it would be even better to provide easy data and model access to anyone who wishes to change these assumptions.

Funding Information This study has been funded by the French-Swedish prize for Young Researchers 2013 jointly awarded by the Embassy of France in Sweden - Institut français de Suède and the French-Swedish Association for Research (AFSR) and benefitting from the patronage of Collège de France. It is also part of Air Pollution Research Implementation in Environmental Leadership (ARIEL) funded by Swedish Research Council FORMAS.

\section{Compliance with Ethical Standards}

Conflict of Interest E. Malmqvist, A. Oudin, M. Pascal and S. Medina declare that they have no conflict of interest.

Human and Animal Rights and Informed Consent This article does not contain any studies with human or animal subjects performed by any of the authors.
Open Access This article is distributed under the terms of the Creative Commons Attribution 4.0 International License (http:// creativecommons.org/licenses/by/4.0/), which permits unrestricted use, distribution, and reproduction in any medium, provided you give appropriate credit to the original author(s) and the source, provide a link to the Creative Commons license, and indicate if changes were made.

\section{References}

Papers of particular interest, published recently, have been highlighted as:

- Of importance

1. WHO, Health risks of air pollution in Europe-HRAPIE. Recommendations for concentration-response functions for costbenefit analysis of particulate matter, ozone and nitrogen dioxide. 2013: Copenhagen.

2. WHO, Review of evidence on health aspects of air pollutionREVIHAAP Project Technical Report B. The WHO European Centre for Environment and Health, Editor. 2013, World Health Organization Europe: Bonn.

3. WHO. Health impact assessment (HIA). 2010 [cited 2017 2017-1123]; Available from: http://www.who.int/hia/en/.

4. Hertz-Picciotto. Epidemiology and quantitative risk assessment: a bridge from science to policy. Am J Public Health. 1995;85(4):484 91. https://doi.org/10.2105/AJPH.85.4.484.

5. Fann N, Bell ML, Walker K, Hubbell B. Improving the linkages between air pollution epidemiology and quantitative risk assessment. Environ Health Perspect. 2011;119(12):1671-5. https://doi. org/10.1289/ehp.1103780.

6. Künsli K, Medina, et al. Public-health impact of outdoor and trafficrelated air pollution: a European assessment. Lancet. 2000;356(9232): 795-801. https://doi.org/10.1016/S0140-6736(00)02653-2.

7. Cohen, et al., Comparative quantification of health risks-outdoor air pollution, in Global and regional burden of disease attributable to selected major risk factors, L.A. Ezzati M, Rodgers A, Murray CJL, Editor. 2004, WHO. p. 1353-1433.

8. WHO. Burden of disease from urban outdoor air pollution for 2008 description of method. 2011 [cited 2014 2014-03-20]; Available from: http://www.who.int/phe/health_topics/outdoorair/databases/ OAP_BoD_2011_.pdf.

9. WHO. Burden of disease from ambient air pollution for 2012 Description of method 2014 [cited 2014 2014-03-25]; 1.3: [Available from: http:/www.who.int/phe/health_topics/outdoorair/ databases/AAP BoD methods March2014.pdf.

10. Van Brusselen D, Arrazola de Oñate W, Maiheu B, Vranckx S, Lefebvre W, Janssen S, et al. Health impact assessment of a predicted air quality change by moving traffic from an urban ring road into a tunnel. The case of Antwerp, Belgium. PLoS One. 2016;11(5): e0154052. https://doi.org/10.1371/journal.pone.0154052.

11. Sabel CE, et al. Public health impacts of city policies to reduce climate change: findings from the URGENCHE EU-China project. Environ Health. 2016;15(Suppl 1):25.

12. OECD, The cost of air pollution. 2014: OECD Publishing.

13. O'Connell and Hurley. A review of the strength and weaknesses of quantitative methods used in health impact assessment. Public Health. 2009;123(4):306-10. https://doi.org/10.1016/j.puhe.2009.02.008.

14. Pope CA 3rd, Burnett R, Thun M, Calle E, Krewski D, Ito K, et al. Lung cancer, cardiopulmonary mortality, and long term exposure to fine particulate air pollution. JAMA. 2002;287(9):1132-41. https:// doi.org/10.1001/jama.287.9.1132. 
15. Beelen R, et al. Effects of long-term exposure to air pollution on natural-cause mortality: an analysis of 22 European cohorts within the multicentre ESCAPE project. Lancet. 2014;383(9919):785-95. ESCAPE study on mortality and air pollution incorporating the inter-urban scale.

16. Pope CA 3rd, et al. Cardiovascular mortality and long-term exposure to particulate air pollution: epidemiological evidence of general pathophysiological pathways of disease. Circulation. 2004;109(1):71-7. https://doi.org/10.1161/01.CIR.0000108927.80044.7F.

17. Burnett, et al. An integrated risk function for estimating the global burden of disease attributable to ambient fine particulate matter exposure. Environ Health Perspect. 2014;122(4):397-403. A novel method of incorporating risk estimates from epidemiological literature.

18. Woodruff G, Schoendorf. The relationship between selected causes of postneonatal infant mortality and particulate air pollution in the United States. Environ Health Perspect. 1997;105(6):608-12. https://doi.org/10.1289/ehp.97105608.

19. Hänninen, K., European perspectives on environmental burden of disease - estimates for nine stressors in six Euuropean countries, K.A. Hänninen O, Editor. 2011, National Institute for Health and Welfare (THL): Helsinki, Finland.

20. Pascal M, Corso M, Chanel O, Declercq C, Badaloni C, Cesaroni G, et al. Assessing the health impacts of urban air pollution in 25 European cities: results from the Aphekom project. Sci Total Environ. 2013;449: 390-400. https://doi.org/10.1016/j.scitotenv.2013.01.077.

21. Brauer M, Amann M, Burnett RT, Cohen A, Dentener F, Ezzati M, et al. Exposure assessment for estimation of global burden of disease attributable to outdoor air pollution. Environ Sci Technol. 2012;46(2):652-60. https://doi.org/10.1021/es2025752.

22. Boldo E, et al. Apheis: health impact assessment of long-term exposure to $\operatorname{PM}(2.5)$ in 23 European cities. Eur J Epidemiol. 2006;21(6):449-58. https://doi.org/10.1007/s10654-006-9014-0.

23. European Commission, Impact assessment - annex to the communication on the thematic strategy on air pollution and the directive on ambient air quality and cleaner air for Europe. 2005, European Union: Brussels p 138.

24. AEAT, Methodology for the cost-benefit analysis of the CAFE Programme - overview of methodology. 2005, AEA technology environment: Oxon, United Kingdom.

25. AEAT, Methodology for the cost-benefit analysis of the CAFE Programme - health impact assessment. 2005, AEA technology environment: Oxon, United Kingdom.

26. Simpson D, Benedictow A, Berge H, Bergström R, Emberson LD, Fagerli H, et al. The EMEP MSC-W chemical transport modeltechnical description. Atmos Chem Phys. 2012;12(16):7825-65. https://doi.org/10.5194/acp-12-7825-2012.

27. WHO. Burden of disease from ambient air pollution for 2012 summary of results. 2014 [cited 2014 2014-03-27]; Available from:
http://www.who.int/phe/health_topics/outdoorair/databases/AAP BoD_results_March2014.pdf?ua $=1$.

28. Pascal M, Corso M, Chanel O, Declercq C, Badaloni C, Cesaroni $\mathrm{G}$, et al. Assessing the public health impacts of urban air pollution in 25 European cities: results of the Aphekom project. Sci Total Environ. 2013;449:390-400. https://doi.org/10.1016/j.scitotenv. 2013.01.077.

29. Simpson, et al., The EMEP MSC-W chemical trasport model-technical descripton. Atmos. Chem. Phys., 2012(12): p. 7825-7865.

30. Hanninen O, et al. Environmental burden of disease in Europe: assessing nine risk factors in six countries. Environ Health Perspect. 2014;122(5):439-46. https://doi.org/10.1289/ehp.1206154.

31. Amann, et al., The current legislation and the maximum technically feasible reduction cases for the CAFE baseline emission projections. 2004, International Institute for Applied Systems Analysis: Luxembourg, Austria.

32. Cohen, et al., The global burden of disease due to air pollution. J Toxicol Environ Health, 2005(68): p. 1-7, 1, DOI: https://doi.org/ $10.1080 / 15287390590523867$.

33. Jerrett, M., et al., Comparing the health effects of ambient particulate matter estimated using ground-based versus remote sensing exposure estimates. Environ Health Perspect, 2016. An important study re-assessing the mortality from air pollution by including the inter-urban scale.

34. Brunekreef B, Miller BG, Hurley JF. The brave new world of lives sacrificed and saved, deaths attributed and avoided. Epidemiology. 2007;18(6):785-8. https://doi.org/10.1097/EDE.0b013e3181570d88.

35. Jerrett M, Arain A, Kanaroglou P, Beckerman B, Potoglou D, Sahsuvaroglu T, et al. A review and evaluation of intraurban air pollution exposure models. J Expo Anal Environ Epidemiol. 2005;15(2):185-204. https://doi.org/10.1038/sj.jea.7500388.

36. Medina S, Ballester F, Chanel O, Declercq C, Pascal M. Quantifying the health impacts of outdoor air pollution: useful estimations for public health action. J Epidemiol Commun Health. 2013;67(6):480-3. https://doi.org/10.1136/jech-2011-200908.

37. Ezzati M, Lopez AD, Rodgers A, Vander Hoorn S, Murray CJL. Selected major risk factors and global and regional burden of disease. Lancet. 2002;360(9343):1347-60. https://doi.org/10.1016/ S0140-6736(02)11403-6.

38. Hunter L, Robb W, Brownie S. The "secret" impact of population statistics on the metrics of diabetes. J Diabetes Metab Disord Control. 2014;1(4) https://doi.org/10.15406/jdmdc.2014.01.00024.

39. Hubbell B, Fann N, Levy J. Methodological considerations in developing local-scale health impact assessments: balancing national, regional, and local data. Air Qual Atmos Health. 2009;2(2):99-110. https://doi.org/10.1007/s11869-009-0037-z. 